\title{
Dorsal Intramedullary Lipoma without Spinal Dysraphism: A Rare Case Report and Review of Literature
}

\author{
Basanta Kumar Baishya ${ }^{1}$ Deep Dutta ${ }^{1}$ Sushant Agarwal ${ }^{2}$ Zakir Hussain ${ }^{1}$ \\ ${ }^{1}$ Department of Neurosurgery, Gauhati Medical College, Guwahati, \\ Assam, India \\ 2 Department of Radiology, Gauhati Medical College, Guwahati, \\ Address for correspondence Deep Dutta, MBBS, MS, Department of \\ Neurosurgery, Gauhati Medical College Guwahati, Assam, India \\ Assam, India
}

Indian J Neurosurg 2016;5:28-30.
Abstract
Keywords
- intramedullary
- lipoma
- dorsal
- spinal dysraphism

\begin{abstract}
Study Design Case report.
Objective The study aims to report a rare case of dorsal intramedullary lipoma, its management, and outcome.

Background We are reporting the rare case of a 23-year-old man with dorsal intramedullary lipoma without spinal dysraphism. The clinical presentation, diagnosis, and management are discussed with relevant review of literature.

Conclusion Intramedullary cord lipoma without spinal dysraphism can be a cause of myelopathy, and proper diagnosis with MRI and subtotal excision preserving the vital cord parenchyma should be the goal, which can give a better outcome.
\end{abstract}

\section{Introduction}

Lipomas, as we know, are universal tumor. Intramedullary lipoma of the spinal cord constitutes less than $1 \%$ of all spinal tumors. ${ }^{1}$ They are hamartoma as stated by few authors. They are mostly seen in the cervicodorsal region in children. ${ }^{1-4}$ They are rare in adults. In the literature, there are in total 12 reported cases of intramedullary lipoma without spinal dysraphism in the dorsolumbar spine till date as per our knowledge. $^{2}$

\section{Case Report}

A 23-year-old man, who presented with spastic ascending paraparesis, with pain and paresthesia of his left thigh. His weakness started in his the left lower limb for the past 4 years and right lower limb for the past 2 years with involvement of the bladder in the form of urgency and frequency. His bowel was constipated. On examination, he had increased tone with a power of 3/5 in both the lower limbs. All modalities of sensation were diminished below D6 bilaterally. His sensation for pain and temperature were diminished more over the left side than the right side. His position sense was impaired below knee over the left side and below ankle over the right side. Vibration sensation was diminished below D6 vertebral level. Perianal sensation was impaired. Abdominal reflex was absent in all four quadrants. Lower limb reflexes were brisk and planters were extensor bilaterally. Romberg's sign was positive. Local examination of the spine did not reveal any spinal dysraphic cutaneous lesions such as hair, sinus, fistula, or dimple.

The magnetic resonance imaging (MRI) of his spine reveals a fairly well-defined intramedullary expansile mass lesion with an exophytic component involving the cord parenchyma opposite D5-D6 interspace to D8-D9 interspace. The lesion shows mixed signals predominantly hyperintense both on T1WI and T2WI. The lesion measures $(1.6 \times 1.14) \mathrm{cm}$ in cross section and $7.56 \mathrm{~cm}$ in craniocaudal dimensions. The lesion shows patchy vertical line restricted diffusion on diffusionweighted imaging (DWI). On postcontrast study there is mild peripheral enhancement. These findings are consistent with nondysraphic intramedullary cord lipoma opposite D5-D6 interspace to D8-D9 interspace (- Figs. 1-3).

Laminectomy was done at D5 to D8 level. A subpial intramedullary lipoma was visualized as yellowish fatty mass on opening the dura. There was no well demarcation between lipoma and the cord parenchyma (-Figs. 4-6). Under microscope subtotal excision of the lipoma was done received

September 22, 2015 accepted

November 18, 2015

published online

February 24, 2016
DOI http://dx.doi.org/

$10.1055 / \mathrm{s}-0036-1572378$. ISSN 2277-954X (c) 2016 Neurological Surgeons' Society of India
License terms

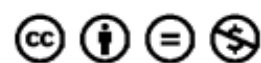




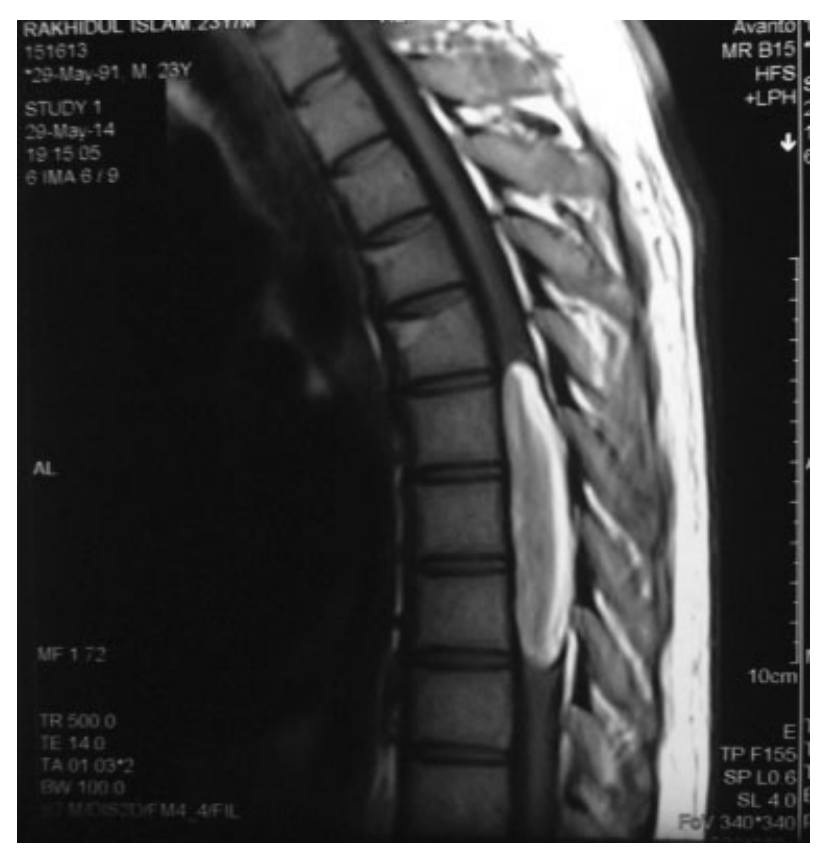

Fig. 1 MRI showing a fairly well-defined intramedullary T1 hyperintense lesion extending from opposite D5-D6 interspace to D8-D9 interspace.

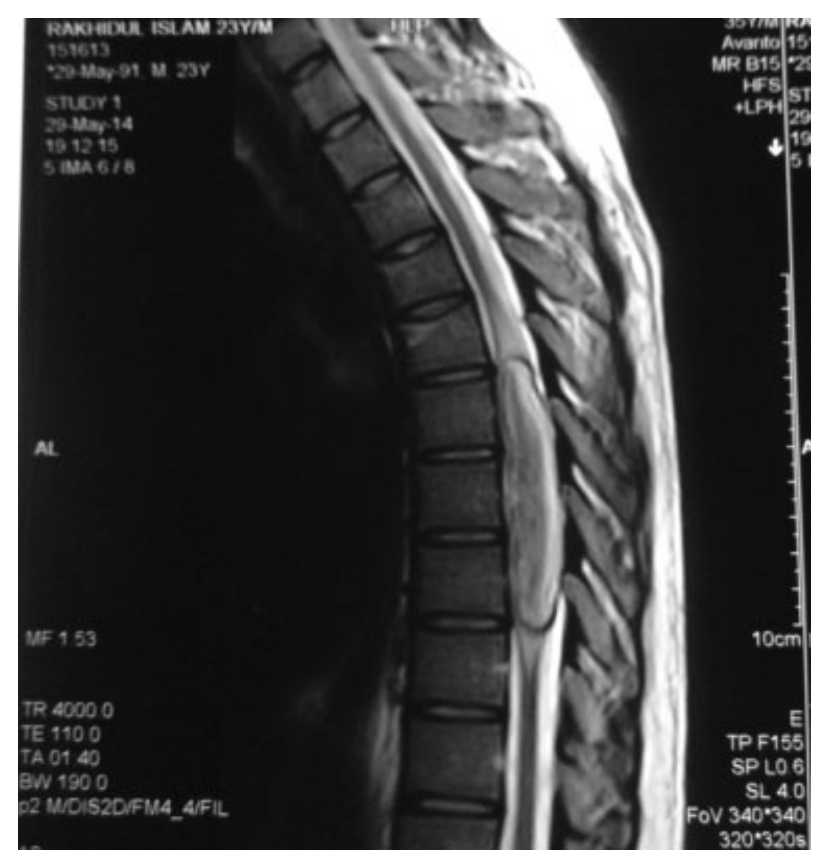

Fig. 2 MRI showing a fairly well-defined intramedullary T2 hyperintense lesion extending from opposite D5-D6 interspace to D8-D9 interspace.

with great care not to injure the underlying cord parenchyma. It was found to be densely adherent to the spinal cord with numerous entering and exiting nerve roots encapsulated. The dura was closed water tightly.

Excised mass was sent for histopathologic examination that confirmed the fatty lipomatous tissue consistent with cord lipoma (-Fig. 7).

Postoperatively patient improved, and on follow-up after 6 weeks, his lower limb power was $-4 / 5$ bilaterally. There was no pain and paresthesia of his lower limbs. There were

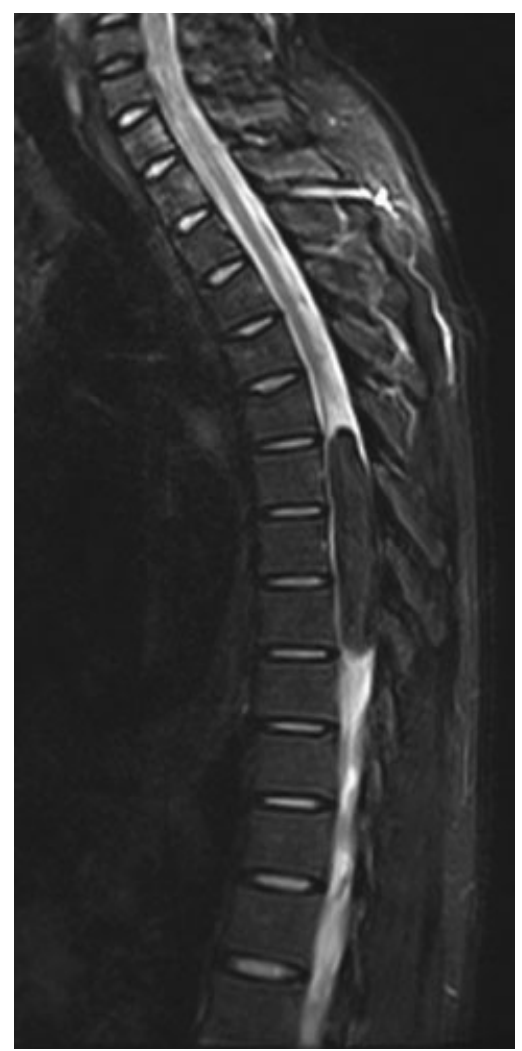

Fig. 3 T2 fat suppressed MRI images showing hypointense signal (signal drop) suggestive of lipoma.

persistent bladder disturbances in the form of increased frequency and urgency.

\section{Discussion}

Lipomas of the spinal cord in adult are very rare lesions . Intramedullary lipomas constitute less than $1 \%$ of all spinal tumors. ${ }^{1,2}$ In the literature till date, there are 12 reported cases of intermedullary lipoma without spinal dysraphism situated in the dorsolumbar region. ${ }^{2}$ They are mostly located in the cervicodorsal region and found mostly in children. ${ }^{1-4}$ The

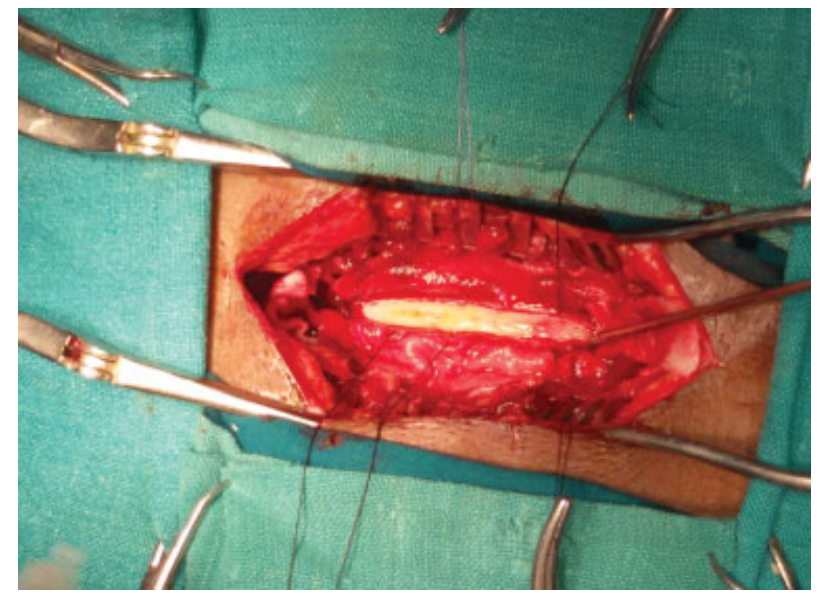

Fig. 4 Operative picture showing the yellowish lipoma with a very less demarcation between normal cord parenchyma and the lesion. 


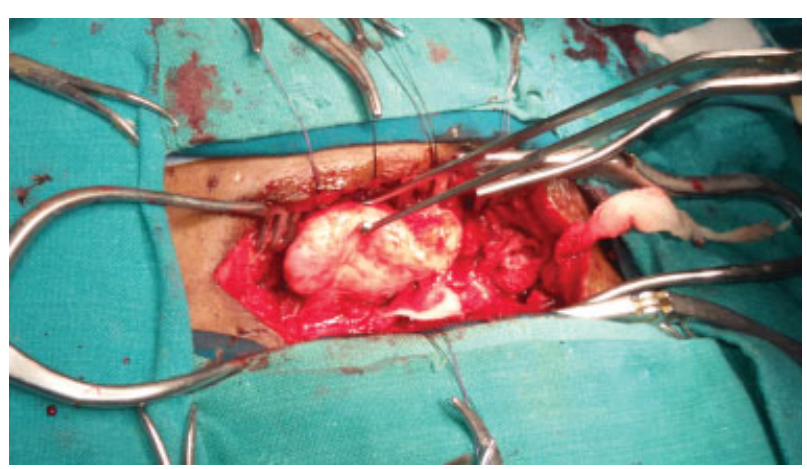

Fig. 5 Intraoperative picture showing lipoma dissection.

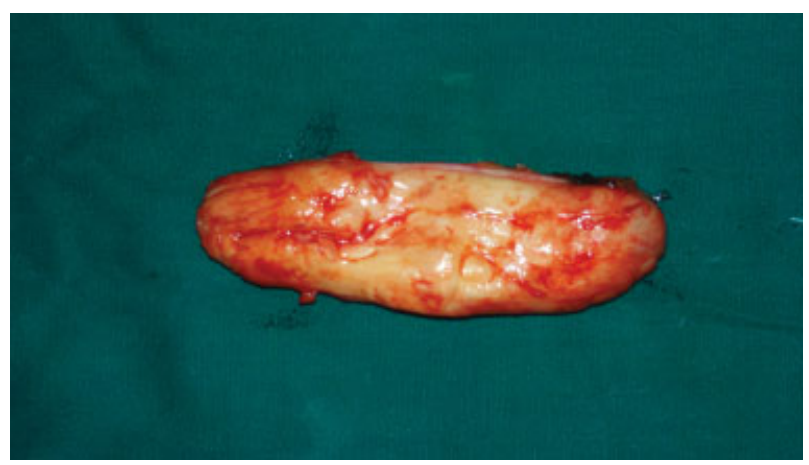

Fig. 6 Figure showing the excised specimen.

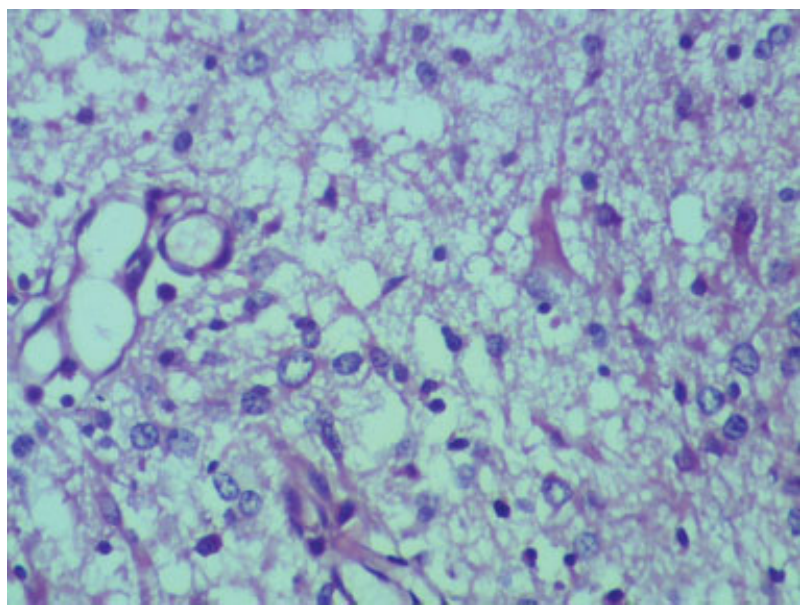

Fig. 7 HPE photograph showing normal fat cells consistent with lipoma.

origin of these lesions are thought to be due to embryonic inclusion in the early fetal life at the time of neural tube closure. ${ }^{5,6}$ Some authors also said that they are hamartomas that arise from fatty tissues, deposition of fat in the connective tissue, and metastatic differentiation of embryonic meninges. 5,6 They may be associated with lipoma at other site in the same patient. ${ }^{7}$ They are very slow-growing tumors, and so patients may present with a long duration of symptoms. Symptoms are according to the location of the tumor. Our patient presented with signs of compressive myelopathy with sensory, motor, and autonomic involvement. MRI is the investigation of choice. In both T1W and T2W images, lipoma appears hyperintense, and in fat suppression images, lipoma tissue appears hypointense. MRI images can give a good tumor delineation from normal cord parenchyma. X-rays and computed tomographic (CT) scan of the spine can give an overview of any bony deformity or any associated congenital malformation or spinal dysraphism. Intramedullary lipoma dissection is a challenge to a neurosurgeons as there is no well demarcation from the normal cord parenchyma and the lesion. It is well established that total excision of the intramedullary lipoma should not be tried, which may lead to a catastrophic result. ${ }^{8,9}$ Use of carbon dioxide laser for resection is ideal for such lesions. ${ }^{2,3,8}$ Intraoperative ultrasonography (USG) is also very useful to identify the extent of the lesion. ${ }^{8}$ We used microsurgical techniques for the excision of the lesion in our hospital. Most of the cases improved neurologically after subtotal resection in a large case series by Bhatoe et al using carbon dioxide laser and by Pruthi and Devi. ${ }^{8,9}$

\section{Conclusion}

Subpial and intramedullary lipoma of the dorsolumbar region in an adult without spinal dysraphism is very rare. These benign lesion should be excised with extreme care not to injure the normal cord parenchyma. The goal of surgery should be tumor debulking and avoiding any neurologic deficit postoperatively.

Conflict of Interest

None declared.

\section{References}

1 Fujiwara F, Tamaki N, Nagashima T, Nakamura M. Intradural spinal lipomas not associated with spinal dysraphism: a report of four cases. Neurosurgery 1995;37(6):1212-1215

2 Srinivasan US, Raghunathan N, Radhi L. Long term outcome of non-dysraphic intramedullary spinal cord lipomas in adults: case series and review. Asian Spine J 2014;8(4):476-483

3 Lee M, Rezai AR, Abbott R, Coelho DH, Epstein FJ. Intramedullary spinal cord lipomas. J Neurosurg 1995;82(3):394-400

4 Fleming KL, Davidson L, Gonzalez-Gomez I, McComb JG. Nondysraphic pediatric intramedullary spinal cord lipomas: report of 5 cases. J Neurosurg Pediatr 2010;5(2):172-178

5 Kasliwal MK, Mahapatra AK. Surgery for spinal cord lipomas. Indian J Pediatr 2007;74(4):357-362

6 Mohindra S, Gupta SK. Cervicobulbar intramedullary lipoma. Spine J 2009;9(3):e12-e16

7 Roka YB, Shrestha M, Puri PR, Adhikari HB. High cervical nondysraphic intradural extramedullary lipoma. Neurol India 2012;60(3):350-351

8 Bhatoe HS, Singh P, Chaturvedi A, Sahai K, Dutta V, Sahoo PK. Nondysraphic intramedullary spinal cord lipomas: a review. Neurosurg Focus 2005;18(2):ECP1-ECP5

9 Pruthi N, Devi BI. Nondysraphic cervical and thoracic intraspinal lipomas: a review. Br J Neurosurg 2010;24(3): $228-232$ 